\title{
Hazards of diazoxide in pulmonary hypertension
}

\author{
J BUCH, A WENNEVOLD
}

From the Cardiovascular Laboratory of Medical Department B, Rigshospitalet, Copenhagen, Denmark

SUMmaRY The use of diazoxide in the treatment of pulmonary hypertension has been advocated recently. We describe three patients who responded less favourably. The first patient had cardiac arrest (asystole) after the acute bolus dose. After recovery only a slight increase in cardiac index was seen while pulmonary vascular resistance was unchanged. The second patient developed total atrioventricular block after the acute bolus dose. After recovery the cardiac index was unchanged while pulmonary vascular resistance was decreased. The third patient felt ill after the acute bolus dose, and the blood pressure dropped, but no conduction abnormalities were noted. The cardiac index rose slightly and the pulmonary vascular resistance was essentially unchanged. Long term treatment with oral diazoxide could not be administered to this patient because abdominal pain and distension developed. Because we lack reliable alternative treatment, it is justifiable to try diazoxide, provided great care is taken.

Vasoconstriction of the pulmonary vascular system plays an important role in the pathogenesis of pulmonary hypertension. Accordingly various vasodilators have been tried in the treatment but the results have in general been unsatisfactory. ${ }^{1}$

Recently, diazoxide has been shown to have a promising effect ${ }^{2}$ and further evaluation was felt to be warranted. We report here the hazards and serious side effects in the use of diazoxide in three patients with primary pulmonary hypertension.

\section{Patients}

CASE 1

A 32-year-old woman had developed symptoms of a collagen disease two years earlier, which was classified as a mixed connective tissue disease with manifestations of both systemic lupus erythematosus and scleroderma. She then developed exertional dyspnoea and had recurrent attacks of pneumonia and pleurisy. She was treated initially with penicillamine and later with large doses of prednisone, with some symptomatic relief. She was admitted after increasing dyspnoea on exertion for six months, and found to be dyspnoeic and mildly cyanosed at rest. There were signs of right sided heart failure consisting of engorgement of the neck veins, liver enlargement, ascites, and peripheral oedema. Pulmonary function tests disclosed a severely impaired diffusion capacity. Received for publication 9 February 1981
Ventilation and perfusion scans showed a decrease in both ventilation and perfusion in the left upper lobe and the right middle and upper lobes. Echocardiography showed signs of considerable pulmonary hypertension with enlargement of the right ventricle. The patient improved somewhat on increased doses of frusemide and digoxin. Right heart catheterisation was performed in order to assess the effect of diazoxide injection into the pulmonary artery. The pressure in the pulmonary artery was $91 / 53 \mathrm{mmHg}$ (mean $66 \mathrm{mmHg}$ ), cardiac index was $0.81 / \mathrm{min}$ per $\mathrm{m}^{2}$, and the pulmonary vascular resistance was 4130 dyne $\mathrm{s} \mathrm{cm}^{-5}$. A bolus dose of diazoxide $(300 \mathrm{mg}$ ) was injected into the pulmonary artery. This induced asystole followed by extreme bradycardia. The patient recovered after resuscitation including intravenous atropine. After an interval of 40 minutes the pressure in the pulmonary artery was $109 / 62 \mathrm{mmHg}$ (mean 77 $\mathrm{mmHg}$ ), the cardiac index was $1.11 / \mathrm{min}$ per $\mathrm{m}^{2}$, and the pulmonary vascular resistance was 4160 dyne $s$ $\mathrm{cm}^{-5}$. Two days later the patient died of progressive respiratory failure. Necropsy confirmed the diagnosis of severe cor pulmonale secondary to vascular changes in the lungs.

CASE 2

A previously healthy 15 -year-old boy was admitted complaining of increasing dyspnoea on exertion of four to five months' duration. He was not in heart failure, but his lips were slightly cyanosed. Clinical 
examination, electrocardiogram, chest $x$-ray, and echocardiography established the diagnosis of primary pulmonary hypertension, which was confirmed at right heart catheterisation, including angiocardiography with contrast injection into the right ventricle. Immediately after the application of $10 \mathrm{ml}$ $1 \%$ lignocaine as local anaesthesia in the right inguinal region, and the introduction of an NIH catheter No. 7 into the femoral vein, the patient developed a vasovagal attack with bradycardia, nausea, and falling blood pressure. After $0.5 \mathrm{mg}$ atropine intravenously this attack soon subsided.

The patient deteriorated despite treatment with increasing doses of hydralazine. After two months right heart catheterisation was repeated in order to test the effect of diazoxide before long-term oral treatment. The pressure in the pulmonary artery was $150 / 90 \mathrm{mmHg}$ (mean $110 \mathrm{mmHg}$ ). The cardiac index was $1.41 / \mathrm{min}$ per $\mathrm{m}^{2}$, and the pulmonary vascular resistance was 4040 dyne $\mathrm{s} \mathrm{cm}^{-5}$. Diazoxide, $50 \mathrm{mg}$, $150 \mathrm{mg}$, and $300 \mathrm{mg}$, was injected through the catheter into the pulmonary artery at intervals of five minutes. Immediately after the last injection the patient developed complete atrioventricular block which lasted for 28 seconds and then disappeared spontaneously. The pressure in the pulmonary artery dropped to $138 / 97 \mathrm{mmHg}$ (mean $111 \mathrm{mmHg}$ ), and in the aorta from $96 / 73$ (mean $81 \mathrm{mmHg}$ ) to $73 / 50$ $\mathrm{mmHg}$ (mean $58 \mathrm{mmHg}$ ); cardiac index was unchanged, and the pulmonary vascular resistance dropped to 2743 dyne $\mathrm{s} \mathrm{cm}^{-5}$.

He developed nausea, vomiting, and abdominal pain and died two days after the investigation. Necropsy showed hypertrophy and dilatation of the right ventricle, medial hypertrophy, and intimal proliferation of the pulmonary artery. No abnormalities were found in the abdomen.

\section{CASE 3}

A 16-year-old boy, second cousin of case 2, was admitted with a history of increasing dyspnoea and syncope on exertion for about three months. He had previously been healthy. The lips and fingernails were mildly cyanosed but he was not in heart failure. On clinical examination, electrocardiogram, chest $x$-ray film, and echocardiography the diagnosis of primary pulmonary hypertension was established.

This patient also deteriorated despite increasing doses of hydralazine and diuretics. After six months a cardiac catheterisation was performed in order to test the effect of diazoxide. The pressure in the pulmonary artery was $120 / 75 \mathrm{mmHg}$ (mean $90 \mathrm{mmHg}$ ). The cardiac index was $1.7 \mathrm{l} / \mathrm{min}$ per $\mathrm{m}^{2}$, and the pulmonary vascular resistance was 2317 dyne $\mathrm{s} \mathrm{cm}^{-5}$. Diazoxide, $50 \mathrm{mg}, 150 \mathrm{mg}$, and $300 \mathrm{mg}$, respectively, was injected through the catheter into the pulmonary artery at five minute intervals; he felt somewhat uneasy one minute after the last injection, but there was no arrhythmia. Initially the pressure in the pulmonary artery dropped to $87 / 50 \mathrm{mmHg}$ (mean 62 $\mathrm{mmHg}$ ) and in the left ventricle from $92 / 4$ to $60 / 0$ $\mathrm{mmHg}$. Five minutes later he felt at ease again, and the pressure in the pulmonary artery had risen to $148 / 90 \mathrm{mmHg}$ (mean $109 \mathrm{mmHg}$ ) and in the left ventricle to $96 / 2 \mathrm{mmHg}$; the cardiac index rose slightly to $2 \cdot 1 \mathrm{l} / \mathrm{min}$ per $\mathrm{m}^{2}$ while the pulmonary vascular resistance was essentially unchanged (2469 dyne $\mathrm{s} \mathrm{cm}^{-5}$ ).

Oral treatment with diazoxide $100 \mathrm{mg}$ three times a day was initiated. After four days he developed diffuse abdominal pain; the abdomen was found to be somewhat distended, with diffuse tenderness, and the liver was grossly enlarged. After withdrawal of the drug, these symptoms subsided and the liver regressed to nearly normal size. Diazoxide treatment was attempted twice more, but each time with a similar result. Finally diazoxide was discontinued, and the patient continued on diuretics and digoxin.

\section{Discussion}

Diazoxide is a potent vasodilator chemically resembling the thiazides. ${ }^{4}$ It has no diuretic property, however, but induces salt and water retention.

A few reports have been published on the use of this drug in the treatment of primary pulmonary hypertension, demonstrating a long-term symptomatic relief and a decrease in pulmonary vascular resistance. $^{23}$

The results presented here have not been so favourable. The first patient developed cardiac arrest after the acute bolus dose. The cardiac index seemed to increase slightly, while pressures increased and pulmonary vascular resistance was unchanged. The haemodynamic results are difficult to interpret because of the intervening cardiac resuscitation. The second patient developed total atrioventricular block after the acute bolus dose, despite a more cautious gradual increase in dosage. Cardiac index was unchanged, while the systolic and diasolic pressure in the aorta, and pulmonary resistance decreased. The third patient felt ill for a few minutes after the bolus dose, while the systemic blood pressure was low, but other adverse effects were not encountered. Cardiac index rose slightly and the pulmonary vascular resistance was unchanged. Treatment with diazoxide orally was not feasible, however, because of side effects which were probably partly caused by the salt and water retaining effect of the drug.

The mechanism behind the reported episodes of asystole and complete atrioventricular block is obscure, but a vagal effect is possible, since the first 
patient immediately recovered after intravenous atropine and the second patient was known to have a labile parasympathetic system, having shown a typical vasovagal attack after injection of the local anaesthetic at an earlier attempt at cardiac catheterisation. Abdominal pain or discomfort is a well-known and frequent side effect of diazoxide. ${ }^{6}$

One of the reasons for our therapeutic failure might be that the two first patients were more severely ill than those previously reported, ${ }^{23}$ as seen from the extremely high pulmonary vascular resistance and very low cardiac index.

Vasodilator treatment of pulmonary hypertension has usually been unsatisfactory. ${ }^{1}$

Recently case reports concerning the beneficial effect of vasodilatation using alpha-blockade by prazosin ${ }^{7}$ or using newer calcium antagonists such as nifedipine ${ }^{8}$ and diltiazem ${ }^{9}$ have been published, but further investigation is needed.

Since no alternative treatment can be recommended, we still believe that a trial of diazoxide is justified, provided great caution is exercised.

\section{References}

1 Klinke WP. Treatment for primary pulmonary hypertension. Am Heart $\mathcal{F}$ 1980; 100: 587-8.
2 Wang SWS, Pohl JEF, Rowlands DJ, Wade EG. Diazoxide in treatment of primary pulmonary hypertension. Br Heart $\mathcal{F}$ 1978; 40: 572-4.

3 Klinke WP, Gilbert JAL. Diazoxide in primary pulmonary hypertension. $N$ Engl f Med 1980; 302: 91-2.

4 Koch-Weser J. Diazoxide. N Engl 7 Med 1976; 294: $1271-4$.

5 Johnson BF. Diazoxide and renal function in man. Clin Pharmacol Ther 1971; 12: 815-24.

6 Saric R, Moreau F, Seguin G, Cohen E, Merlet M, Lorin $\mathrm{J}-\mathrm{L}$. Le traitement prolongé des hypoglycémies sévères par le diazoxide. Sem Hop Paris 1974; 50: 1497-503.

7 Levine TB, Rose T, Kane M, Weir EK, Cohn JN. Treatment of primary pulmonary hypertension by alpha adrenergic blockade (abstract). Circulation 1980; 62, suppl III: 26.

8 Camerini F, Alberti E, Klugmann S, Salvi A. Primary pulmonary hypertension: effects of nifedipine. Br Heart $\mathcal{f}$ 1980; 44: 352-6.

9 Kambara H, Fujimoto K, Wakabayashi A, Kawai C. Primary pulmonary hypertension: beneficial therapy with diltiazem. Am Heart f 1981; 101: 230-1.

Requests for reprints to Dr Jan Buch, Cardiovascular Laboratory of Medical Department B, Rigshospitalet, Blegdamsvej 9, 2100 Copenhagen $\emptyset$, Denmark. 